\title{
Effect of Salt and Liver/Fat Ratio on Microstructure, Emulsion Stability, Texture and Sensory Mouth Feel of Liver Paste
}

\author{
Liselot Steen • Ilse Fraeye • Olivier Goemaere • \\ Laurence Sifre • Bart Goderis • Hubert Paelinck • \\ Imogen Foubert
}

Received: 24 September 2013 / Accepted: 17 December 2013

(C) Springer Science+Business Media New York 2014

\begin{abstract}
This paper reports the effect of two liver/fat ratios (35/35 and 20/50) and two salt levels (0 and $1.8 \%$ ) on the microstructure, emulsion stability, textural and sensorial properties of spreadable liver paste. The conventional liver paste, a hot emulsion, consists of fat globules surrounded by a protein layer and dissolved proteins in a continuous phase forming a gel matrix. Addition of salt led to a microstructure with smaller fat globules and increased fat binding properties, causing more stable emulsions. This was attributed to an increased solubilisation of the liver proteins which are available for gel formation and as emulsifier, resulting in a harder, less spreadable product. The microstructure and emulsion stability were highly influenced by the liver/fat ratio. A lower liver/fat ratio resulted in a more heterogeneous microstructure with bigger fat globules and the formation of fat channels throughout the structure of the product. Less gelling proteins were dissolved in the continuous phase and also a smaller amount of proteins were available to act as emulsifier.
\end{abstract}

L. Steen $(\bowtie) \cdot$ I. Fraeye $\cdot$ O. Goemaere $\cdot$ H. Paelinck

Research Group for Technology and Quality of Animal Products,

KU Leuven Campus Gent (KAHO Sint-Lieven), Gebroeders De

Smetstraat 1, B-9000 Gent, Belgium

e-mail: liselot.steen@kahosl.be

L. Steen $\cdot$ I. Fraeye $\cdot$ I. Foubert

Research Unit Food \& Lipids, KU Leuven Kulak,

Etienne Sabbelaan 53, B-8500 Kortrijk, Belgium

L. Sifre

Histalim, 126 rue Emile Baudot, F-34000 Montpellier, France

B. Goderis

Polymer Chemistry and Materials Division, Chemistry Department,

KU Leuven, Celestijnenlaan 200f, B-3001 Leuven, Belgium

L. Steen $\cdot$ I. Fraeye $\cdot$ O. Goemaere $\cdot$ H. Paelinck $\cdot$ I. Foubert

Leuven Food Science and Nutrition Research Centre (LFoRCe),

Department of Microbial and Molecular Systems (M2S),

KU Leuven, Kasteelpark Arenberg 20, B-3001 Leuven, Belgium
Although less stable emulsions were formed, the liver/fat ratio did not affect the hardness of liver paste. These results suggest that both liver protein gelation and fat crystallization contribute to the hardness of liver paste.

Keywords Liver pâté $\cdot$ Salt $\cdot$ Liver/fat ratio $\cdot$ Microstructure . Meat emulsion stability $\cdot$ Texture

\section{Introduction}

Liver paste products are meat products manufactured and consumed all over the world, although in Europe they are mainly consumed in France, Germany, Denmark, Spain and Belgium (Russell et al. 2003; Perlo et al. 1994). Generally, these products are classified according to their main stabilizing processing treatment: they can be processed raw (e.g. liver sausage) or precooked (e.g. spreadable liver paste) (Allais 2010). This article deals with spreadable liver paste, which is a warm processed meat product composed of liver, fat, salt, water and small amounts of auxiliary compounds. The product has the characteristics of an oil-in-water $(\mathrm{O} / \mathrm{W})$ emulsion in which liver proteins act as the main emulsifying agent, forming an interfacial protein film around the fat particles (Hilmes et al. 1993; Allais 2010).

Analysing the open literature in the field, it is clear that only a few publications have dealt with the composition of spreadable liver pastes and its effect on the microstructure. Katsaras et al. (1987) used optical and scanning electron microscopy to study the morphology of warm processed spreadable meat containing liver sausages after heating the liver to different temperatures and adding different amounts of salt. They observed that comminution and salting resulted in the formation of a granular-thread network of hydrated liver proteins. When the salted liver batter was added to the hot meat/fat fraction, a globular-granular liver protein network was formed, 
consisting of fat particles which were completely or partially enclosed by liver proteins. During cooking, the liver protein matrix became dense thus immobilizing the fat particles. Cheong and Fischer (1993) also investigated the microstructural aspects of spreadable liver paste. They used scanning electron microscopy to study the effect of emulsifiers and concluded that the most effective emulsifier (a monoglyceride of stearic acid) resulted in a highly stable product with an even and fine fat droplet size distribution together with a full enclosure of the fat droplets with proteins. Delgado-Pando et al. (2012) studied the structure of a liver paste in which the fat content was reduced and the animal fat was replaced with an n-3 PUFA/konjac gel by determining the viscoelastic properties. Steen et al. (2013) determined the viscoelastic properties of liver paste and the intermediates in the processing of liver paste. The effect of two different liver/fat ratios and the addition of salt were examined as well. They concluded that the viscoelastic parameters [linear viscoelastic region (LVR), $\mathrm{G}^{\prime}$ and $\left.\mathrm{G}^{\prime \prime}\right]$ of liver paste increased with the addition of salt, resulting in a stronger and more stable product. The liver/ fat ratio did not affect the viscoelastic parameters $G^{\prime}$ and $G^{\prime \prime}$. This might be attributed to a more extensive crystallization of the fat in the liver paste with a low liver/fat ratio, which besides liver protein gelation during heat treatment also aids to structure building of liver paste. However, the structural contribution by the proteins seemed to be more stress resistant than the structure generated by fat crystallization, as reflected by the longer LVR for the liver paste with the highest liver/fat ratio. Moreover, none of these studies investigated the macroscopic properties to study the relationship between the microstructure and macroscopic properties in spreadable liver pastes.

A limited number of publications have dealt with the composition of spreadable liver pastes and its effect on the macroscopic properties, more specifically texture and cooking loss. However, none of these studies paid attention to explaining the observed changes in macrostructure. Hammer (1981) has drawn up three-dimensional (3D) composition diagrams, representing the amount of liver, adipose tissue and muscular tissue, indicating the regions of cooking loss expressed as fat and jelly depositions. From those diagrams, it can be concluded that the main remedy for jelly deposition is an increase in the amount of adipose tissue, while to eliminate fat deposition, the amount of liver should be increased. The latter observation was confirmed by Hammer (1988a; b), Hilmes et al. (1993), Fisher et al. (1991), Cheong and Fisher (1991) and Cheong and Fisher (1992). Several authors have investigated the influence of the addition of different types of emulsifiers to liver paste. For high liver content products, no emulsifiers seem to be necessary to obtain a stable product (Fisher et al. 1991; Cheong and Fisher 1991 \& Cheong and
Fisher 1992). However, Pyrcz et al. (2005) observed that emulsifiers reduce the fat and jelly separation and improve the physicochemical properties of the end product. Depending on the emulsifier used, addition to critical products can reduce but not fully eliminate fat separation (Hammer, 1988a; b \& Hammer 1981). Pyrcz et al. (2006) investigated the influence of three different origins of liver (porcine, poultry and rabbit liver) on the macroscopic properties of liver paste. They concluded that liver products produced with poultry and rabbit liver had the lowest cooking loss. Schneider et al. (1998) and Jaud et al. (1998) studied the effect of different fat types on the stability of the liver paste batter determined by conductivity measurements and fat separation measurement on the final product. The more unsaturated fatty acids in the adipose tissue, the more stable the product. This is in contrast with Hammer (1981), who did not observe any effect of the type of adipose tissue. No studies could be found that describe the effect of salt on the macrostructural properties of spreadable liver paste.

The objective of this study is to investigate the effect of two composition parameters (liver/fat ratio and salt) on the microstructure, emulsion stability and macroscopic properties of spreadable liver paste and to gain understanding into the relationship between those different structural levels, as this has not been studied before. To study the effect of both composition variables and study the effect of more and less stable products, a high (35/35, conventional formulation) and low (20/50) liver/fat ratio was chosen. A $1.8 \%$ salt was selected because liver paste products commonly contain $1.8 \%$ salt. Katsaras et al. (1987) claimed that a liver protein structure can develop without salt addition. Therefore, a second salt level of $0 \%$ was chosen. The same set of composition and processing parameters was applied as described in the previous paper which studied the dynamic rheological properties of spreadable liver paste (Steen et al. 2013). This allows correlating the current results to the rheological behaviour.

\section{Material and Methods}

\section{Manufacturing of Liver Paste}

The spreadable liver pastes, further called liver pastes, were prepared in the pilot plant of the research group for Technology and Quality of Animal Products of KAHO Sint-Lieven. Each liver paste formulation was prepared in triplicate.

Fresh pork liver and fresh pork back fat were obtained from a local industrial slaughterhouse. Pork liver was ground and pork back fat was chopped as described by 
Steen et al. (2013), vacuum-packed separately and frozen $\left(-18^{\circ} \mathrm{C}\right)$ until preparation.

The effect of a high (35/35) and low (20/50) liver/fat ratio and two salt levels $[0 \%=$ without salt (NS) and $1.8 \%=$ with salt (S)] was studied (Table 1), resulting in four different formulations: $35 / 35 \mathrm{NS}, 35 / 35 \mathrm{~S}, 20 / 50 \mathrm{NS}$ and 20/50 S. The $35 / 35 \mathrm{~S}$ represents the conventional formulation. No meat tissue or additional emulsifiers were used to manufacture the liver pastes, in order to eliminate unnecessary complexity and confounding effects. The other ingredients were as reported by Steen et al. (2013). The liver paste products were manufactured according to Fig. 1. Firstly, the frozen liver $\left(-3{ }^{\circ} \mathrm{C}\right)$ was pre-chopped with sodium chloride (only for the liver pastes containing salt) and sodium nitrite. The liver batter was stored at $4{ }^{\circ} \mathrm{C}$ until further processing. Secondly, the scalded back fat (boiled at $100{ }^{\circ} \mathrm{C}$ during $20 \mathrm{~min}$ ) was chopped together with part of the broth. Finally, when the temperature reached $51^{\circ} \mathrm{C}$, the liver batter with the remaining ingredients were added and mixed to obtain the liver paste batter. The specific manufacturing conditions for preparations of these liver pastes are detailed by Steen et al. (2013). When processing was complete, the liver paste batters were filled into cans (diameter $7 \mathrm{~cm}$, height $5 \mathrm{~cm}, 250 \mathrm{~g}$ ) and heated at $76^{\circ} \mathrm{C}$ (core temperature $74^{\circ} \mathrm{C}$ ). After $1.5 \mathrm{~h}$ cooking, the cans were cooled to $4{ }^{\circ} \mathrm{C}$ and stored at that temperature for 1 week, after which they were analysed.

\section{Microstructure}

From each liver paste sample, six subsamples were cut and paraffin-embedded according to the NF V 04-417 standard (AFNOR 1999). Three micrometer paraffin sections were stained with picro-indigo carmine by using Calleja's method (Martoja and Martoja 1967). Specimens were observed using a Leica DM4000 B/M microscope (Leica Microsystems GmbH, Wetzlar, Germany) and a digital camera Infinity 2-1C (Lumenera, Ottowa, Canada), at a 50-fold magnification. The most representative micrograph of each liver paste variant was selected. The greenish image contrast was converted into grey tones and flattened by normalization with a 2D polynomial describing the global, large scale intensity distribution using the program FIT2D version 12.034 (Hammersley 1998). Specific features within the flattened grey tone images were colour marked, using standard functions within Photoshop version 7.0. Starting from binarised and appropriately masked
Table 1 Recipe (\% ingredients) used for liver pastes with different liver/ fat ratios and with and without salt

\begin{tabular}{lllll}
\hline Ingredient (\%) & $35 / 35 \mathrm{NS}$ & $35 / 35 \mathrm{~S}$ & $20 / 50 \mathrm{NS}$ & $20 / 50 \mathrm{~S}$ \\
\hline Liver & 35 & 35 & 20 & 20 \\
Back fat & 35 & 35 & 50 & 50 \\
Water & 30 & 30 & 30 & 30 \\
Salt & 0 & 1.8 & 0 & 1.8 \\
Sodium nitrite & 0.012 & 0.012 & 0.012 & 0.012 \\
Sodium ascorbate & 0.05 & 0.05 & 0.05 & 0.05 \\
Glucose & 0.5 & 0.5 & 0.5 & 0.5 \\
Spices & 0.8 & 0.8 & 0.8 & 0.8 \\
\hline
\end{tabular}

$N S$ without salt, $S$ with salt

images, the two-dimensional (2D) fat particle size distribution was determined using the particle area determination function of $\mathrm{V}$ for Windows (version 3.5b, Digital Optics Ltd). The resulting particle areas were translated into a corresponding 2D particle diameter assuming perfect spherical shapes. Using Microcal Origin version 6.0, histograms were constructed, representing the total area occupied by spheres of a given radius. After normalization to the total histogram area, the histograms were approximated by log normal distributions as implemented in Microcal Origin. This procedure yielded values for the mode (maximum probability), average and median 2D fat particle diameter. Recall that all values are area weighted. Note that sizes extracted from 2D cross sections always represent underestimations of the actual 3D object sizes. Being merely interested in qualitative differences, no efforts were made to translate the obtained 2D distributions to 3D.

\section{Emulsion Stability}

The methodology to study emulsion stability of the liver paste products was based on the procedure by Hughes, Cofrades and Troy (1997). The raw liver paste batter (30 g) was placed in a pre-weighted centrifuge tube. The sample was heated in a cooking chamber for $30 \mathrm{~min}$ at $70{ }^{\circ} \mathrm{C}$ and centrifuged for $3 \mathrm{~min}$ at $4,025 \mathrm{~g}$. The supernatant was poured into a preweighed crucible, dried overnight at $100^{\circ} \mathrm{C}$ and weighed. The centrifuge tube with the remaining pellet was also weighed. The percentage of total expressible fluid (\%TEF) (mixture of fat and water from the supernatant), fat (\% Fat) and water (\% Water) were calculated as follows:

\footnotetext{
$\% \mathrm{TEF}=[($ weight centrifuge tube and sample $)-($ weight centrifuge tube and pellet $)] /$ sample weight $\times 100 \%$

$\%$ Fat $=$ weight of dried supernatant $/$ sample weight $\times 100 \%$

$\%$ Water $=[($ weight supernatant $)-($ weight dried supernatant $)] /$ sample weight $\times 100 \%$
} 
Fig. 1 Schematic overview of liver paste processing

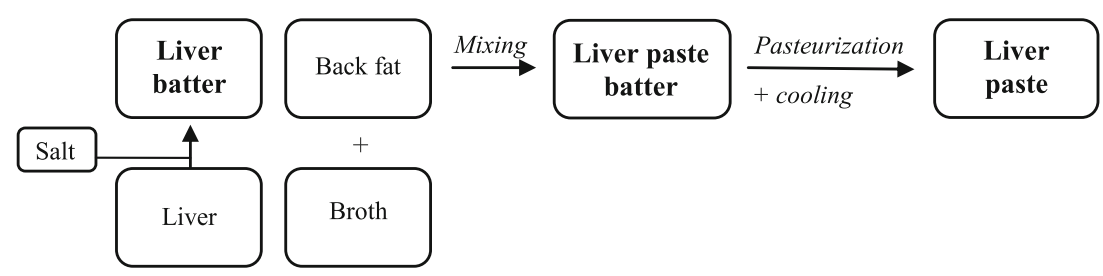

As described above, each liver paste formulation was prepared in triplicate. Of each liver paste preparation, three samples were analysed.

\section{Texture}

Texture Profile Analysis (TPA) of the liver pastes was performed using a Lloyd Texture Analyzer (Model LF plus, Lloyd Instruments Ltd, Fareham, Hampshire, England) as described by Bourne (1978). Cans (diameter $7 \mathrm{~cm}$, height $5 \mathrm{~cm}, 250 \mathrm{~g}$ ) with liver paste were axially penetrated to $40 \%$ of their original height. Force-distance deformation curves were derived using a $100 \mathrm{~N}$ load cell and a cylindrical probe (diameter $6 \mathrm{~mm}$ ) at a constant crosshead speed of $100 \mathrm{~mm} / \mathrm{min}$. The textural parameters were directly obtained from the recorded force-distance curves: the hardness $(\mathrm{N})$ is the maximum force required to penetrate the sample $40 \%$; the cohesiveness (-) is how well the product withstands a second deformation relative to how it behaved under the first deformation $\left(A_{2} / A_{1}\right)$, with $A_{1}$ and $A_{2}$ the total energy required for the first and second penetration, respectively; the gumminess $(\mathrm{N})$ is the force needed to disintegrate a semisolid food to a state ready for swallowing and is defined as hardness $\mathrm{x}$ cohesiveness; the springiness $(\mathrm{mm})$ is the ability of the sample to recover to its original state after the deforming force is removed; the chewiness $(J)$ is the energy required to chew a solid food to a state ready for swallowing and is defined as springiness $\mathrm{x}$ gumminess; and the adhesiveness (J) is the work necessary to overcome the attractive forces between the surface of the food and the surface of the probe.

Spreadability tests were also performed with a Lloyd Texture Analyzer. A $100 \mathrm{~N}$ load cell with a $45^{\circ}$ cone probe was used to penetrate $10 \mathrm{~mm}$ into the liver paste at a speed of $100 \mathrm{~mm} / \mathrm{min}$ and a holding time of $30 \mathrm{~s}$. Spreadability is expressed as the area of work $(\mathrm{N} \mathrm{mm})$ between the peak force at which the probe is at its maximum penetration depth and the final force recorded after a 30-s hold. The smaller the value, the higher the spreadability because easily spreadable liver pastes require smaller forces over holding time.

The texture profile and spreadability measurements were performed at $4{ }^{\circ} \mathrm{C}, 7$ days after preparation. For each liver paste formulation (prepared in triplicate), three samples were evaluated and each sample was analysed three times, at three different locations.
Descriptive Sensory Analysis

Samples were evaluated for sensory analysis using Quantitative Descriptive Analysis (QDA). Tests were carried out in an individual panel room. The eight panellists, familiar with sensory analysis of meat products, were asked to evaluate the four liver paste samples on four mouth feel attributes ('creaminess', 'hardness', 'wateriness' and 'graininess'). A plate including the four liver paste samples which were each coded with three random digit numbers was provided to each panellist. Liver pastes were equilibrated at room temperature for $15 \mathrm{~min}$ before testing. The intensity of the four attributes was quantified using an unstructured intensity scale from 0 to $100 \mathrm{~mm}$, which was anchored to the left on ' $0 \mathrm{~mm}$ ' (=attribute not detected) and to the right on ' $100 \mathrm{~mm}$ ' (=attribute extremely strong). After sensory analyses, scores for each attribute were quantified as distance from the ' $0 \mathrm{~mm}$ ' in millimetres.

The QDA test with the four liver paste formulations was performed in triplicate. For each QDA test, a different replication of every liver paste formulation was used.

\section{Statistical Analysis}

A $2 \times 2$ factorial design was set up to analyse the effect of liver/ fat ratio and salt by analysis of variance (ANOVA) via the general linear model. Statistical analysis was performed using SPSS version 16.0. The level of significance for all tests was set at $p<0.05$.

\section{Results and Discussion}

\section{Microstructure}

Figure 2 shows the light micrographs of the liver paste emulsions. The conventional (35/35 S, Fig. $2 b$ ) liver paste has the characteristics of an emulsion in which fat droplets (white) surrounded by a visible dark soluble protein layer are uniformly distributed in a continuous phase. Most of the fat globules are round-oval shaped, and the average diameter is $10.3 \mu \mathrm{m}$ (Table 2). The continuous phase of the conventional liver paste (35/35 S) consists of water with dissolved proteins (dark) in which adipocytes (yellow) and insoluble parts of 
Fig. 2 Light micrographs of liver paste emulsions 35/35 NS (a), 35/ $35 \mathrm{~S}$ (b), 20/50 NS (c) and 20/50 S (d). Colour codes: white $=$ fat droplets; yellow = fat adipocytes; green $=$ fat coalescence; red=insoluble parts of connective tissue fragments, nerves, and so on; and Bar $=100 \mu \mathrm{m} . N S$ without salt, $S$ with salt

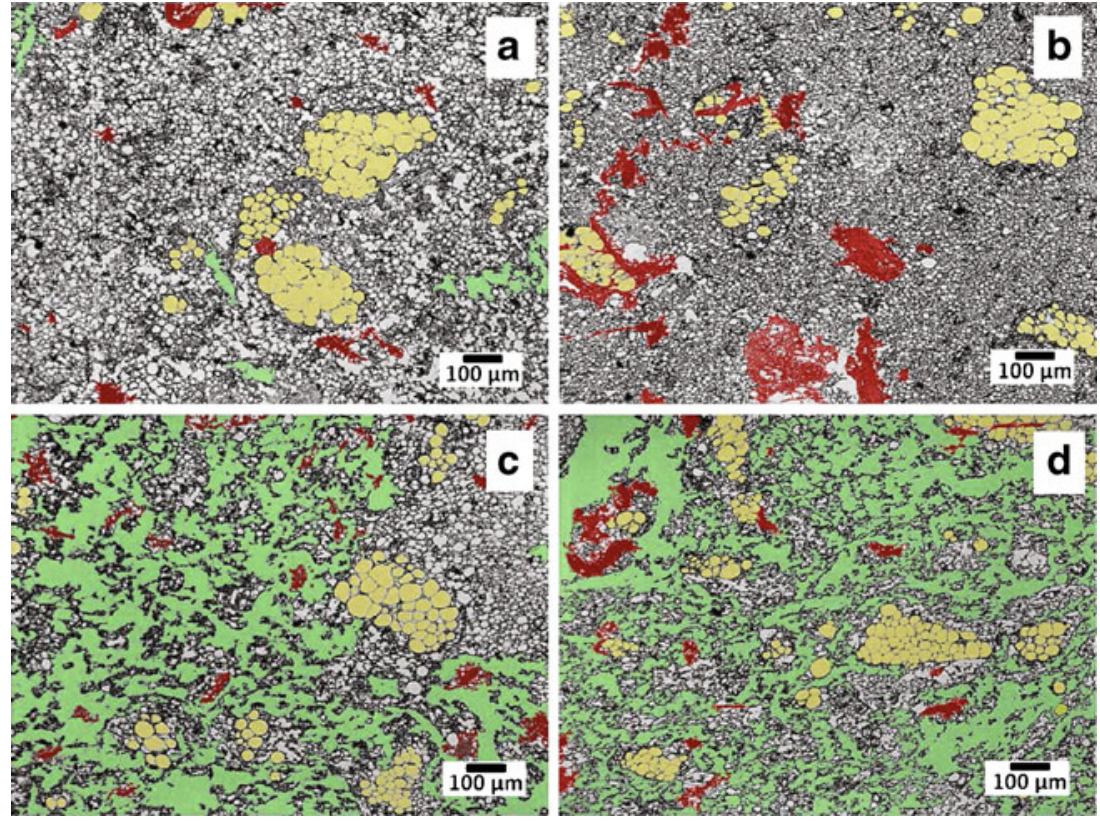

connective tissue fractions, vascular fragments, nerves (red), and so on are dispersed. The proteins dissolved in the continuous phase probably form a gel, which increase the viscosity of the continuous phase and thus, according to Stokes' law, contribute to the stability of the emulsion. Although the adipose tissue is heated to prepare the liver pastes, some of the adipocytes still remain intact after processing. Katsaras et al. (1987) studied the morphology of a warm processed spreadable liver sausage (containing meat) and observed a similar microstructure in which fat particles are finely distributed and enclosed by liver proteins. When comparing the light micrographs of the four liver pastes (Fig. 2), it is clear that salt and liver/fat ratio affected the microstructure.

Addition of salt in liver paste 35/35 (35/35 S) (Fig. 2b) resulted in smaller and more uniform fat globules with no fat channels (Table 2). This effect can be attributed to the extraction of the salt soluble liver proteins. The solubilisation effect of salt on the salt soluble liver proteins is most likely caused by a screening of the attracting charged groups of the proteins and/or by inducing a weakening of intermolecular hydrogen bonds in the more polar salt containing medium (chaotropic effect). According to Nuckles et al. (1990), liver proteins derived from pork liver contain $76 \%$ water soluble proteins, $15 \%$ salt soluble proteins and $9 \%$ insoluble proteins. As a

\begin{tabular}{llll}
$\begin{array}{l}\text { Table } 2 \text { Effect of salt } \\
\text { and liver/fat ratio on fat } \\
\text { globule diameter of liver }\end{array}$ & Treatment & \multicolumn{2}{l}{ Particle diameter $(\mu \mathrm{m})$} \\
\cline { 2 - 4 } paste & $35 / 35 \mathrm{NS}$ & 21.4 & 16.1 \\
& $35 / 35 \mathrm{~S}$ & 10.3 & 5.6 \\
& $20 / 50 \mathrm{NS}$ & 19.1 & 13.8 \\
$N S$ without salt, $S$ with & $20 / 50 \mathrm{~S}$ & 20.6 & 18.8 \\
salt & &
\end{tabular}

result, with salt, more liver proteins are available to act as an emulsifier which leads to a finer emulsion. Indeed, according to McClements (2005), the minimum size of stable droplets in a food emulsion is known to decrease by increasing emulsifier concentration.

Decreasing the liver/fat ratio resulted in the formation of a more heterogeneous microstructure consisting of nonemulsified and emulsified zones. The non-emulsified zones were characterized by fat globule coalescence and the formation of fat channels (represented by the green zones in the micrographs) while the emulsified zones were characterized by irregularly shaped fat globules surrounded by a protein layer. Decreasing the liver/fat ratio resulted in bigger fat globules as seen in Table 2 (only for the salt containing variant). Indeed, more fat is present, while less proteins are available for adsorption at the oil/water interface which leads to an emulsion with bigger droplets and fat coalescence.

\section{Emulsion Stability}

Measurements of emulsion stability are indicative of hydration/binding properties and give information about the ability of meat emulsions to retain moisture and fat upon further processing (Lurueña-Martinez et al. 2004).

The results regarding emulsion stability are shown in Fig. 3. In this study, the mean values of \% TEF for all liver pastes are rather high compared to other studies on (cold) meat emulsions (e.g. Carballo et al. 1995; Hughes et al. 1997; Lurueña-Martinez et al. 2004; Miklos et al. 2011). The relatively weak fat and moisture retentions are due to the fact that the liver pastes were formulated without additional emulsifiers (e.g. sodium caseinate) or any other binding 


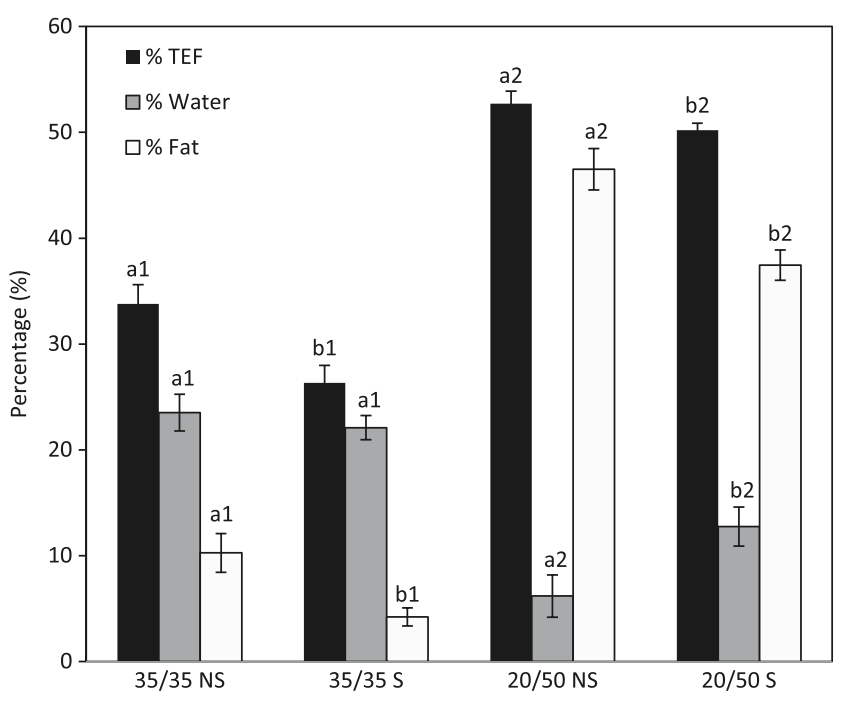

Fig. 3 Emulsion stability of liver pastes prepared with liver/fat ratio $35 / 35$ or $20 / 50$, with (S) our without salt (NS). Grey bars illustrate the amount of water (\% Water) while the white bars illustrate the amount of fat separated ( $\%$ Fat), both calculated in percentage batter weight. The black bars illustrate the amount of total expressible fluid $(\% \mathrm{TEF})$. Means and standard deviation are presented $\left(C_{n}=9\right) . a, b$ Effect of salt: within the same liver/fat ratio, means with different letter indicate significant difference at $p<0.05 .{ }^{1,2}$ Effect of liver/fat ratio: within the same salt variant, means with different number indicate significant difference at $p<0.05$

agents (e.g. phosphate and carrageenan) in order to enlarge the effect of salt and the raw materials and emphasize possible improvements.

In Fig. 3 it can be seen that the addition of salt caused significantly lower values of \% TEF, irrespective of the liver/ fat ratio, although the effect was more pronounced for the liver paste $35 / 35$. Total expressible fluid consists of jelly/water ( $\%$ Water) and fat (\% Fat). The \% Water and \% Fat in Fig. 3 are expressed relatively to the total liver paste mass. However, the same conclusions could be drawn when the amount of water and fat were expressed relative to the total amount of water and fat. It is clear that addition of salt caused significantly lower values of $\%$ Fat, while the influence on \% Water was less clear. The effect on both parameters was more pronounced for the liver paste 20/50. These results indicate that in the presence of salt liver proteins had better emulsifying properties. This agrees with the results obtained by Hand et al. (1987) who showed that salt had a positive effect on emulsion stability in frankfurters, although this is a cold emulsion. The decrease in \% Fat caused by salt can mainly be explained based on the microstructural characteristics of the products, as discussed above. Addition of salt results in more extensive solubilisation of proteins with more proteins which can act as emulsifier, allowing the formation of a finer emulsion with more emulsified fat as seen in the light micrographs. Furthermore, the viscosity of the continuous phase is probably increased by the gelling ability of the proteins, which are expected to be present in higher amounts in the continuous phase. Based on both phenomena (smaller fat globules and higher viscosity of the continuous phase), Stokes' law indeed predicts a slower phase separation under applied centrifugational force, hence a better emulsion stability.

As seen in Fig. 3, a lower liver/fat ratio (20/50) resulted in a strong increase of $\%$ TEF which could be attributed to an increase in $\%$ Fat, as the $\%$ Water decreased. The effect on $\%$ Fat and \% Water was more pronounced for the liver paste without salt. The same phenomenon is also reflected in the results of Hammer (1981) who suggested that the main remedy for jelly separation is an increase in the amount of adipose tissue, while to eliminate fat deposition, the amount of liver should be increased. The latter observation was confirmed by Hammer (1988a; b), Hilmes et al. (1993), Schneider et al. (1998), Fischer et al. (1991), Cheong and Fischer (1991) and Cheong and Fischer (1992).

Again, the effect on \% Fat can be explained by Stokes' law and the microstructural features as discussed above. A liver paste with a lower liver/fat ratio includes more fat and less liver proteins available to act as emulsifier which led to a heterogeneous emulsion with larger fat globules and the occurrence of non-emulsified zones and fat channels. This, together with probably less gelling proteins in the continuous phase resulted in movement of the fat towards the surface of the product during centrifugation.

In conclusion, the liver paste emulsions with a liver/fat ratio $35 / 35$ were the most stable emulsions. The emulsion stability of those liver paste emulsions was improved when salt was added to the formulation. Steen et al. (2013) studied the effect of liver/fat ratio and salt on the viscoelastic properties of spreadable liver paste and observed that the LVR in spreadable liver pastes also increased with addition of salt and a higher liver/fat ratio. The widest LVRs were observed for the liver pastes $35 / 35 \mathrm{NS}$ and $35 / 35 \mathrm{~S}$ which is consistent with the fact that they had the lowest values for TEF as shown in Fig. 3. Therefore, better emulsifying and binding properties expressed as \% TEF may be related to a greater structural strength of liver paste, as indicated by the length of LVR.

\section{Texture}

In Table 3, it can be seen that addition of salt caused significantly higher values for hardness, springiness, gumminess and chewiness and was more pronounced for liver paste 20/50, except for springiness where no significant interaction was determined. No significant differences could be observed for cohesiveness and adhesiveness. Addition of salt also resulted in a significantly higher spreadability value which indicates that with salt, liver pastes are more difficult to spread. In this case, no interaction could be determined between both variables. There is no literature available on the effect of salt on the texture of liver paste. Still, the results in the present study can be compared with cold meat emulsions. Jiménez- 
Table 3 Effect of salt and liver/fat ratio on texture profile analysis parameters and spreadability of liver paste

\begin{tabular}{lcrrr}
\hline Treatment & \multicolumn{1}{c}{$35 / 35 \mathrm{NS}$} & \multicolumn{1}{l}{$20 / 50 \mathrm{NS}$} & \multicolumn{2}{c}{$20 / 50 \mathrm{~S}$} \\
\hline Hardness (N) & $0.78 \pm 0.03^{\mathrm{a}, 1}$ & $1.02 \pm 0.06^{\mathrm{b}, 1}$ & $0.69 \pm 0.03^{\mathrm{a}, 2}$ & $1.02 \pm 0.16^{\mathrm{b}, 1}$ \\
Cohesiveness (-) & $0.551 \pm 0.01^{\mathrm{a}, 1}$ & $0.550 \pm 0.01^{\mathrm{a}, 1}$ & $0.547 \pm 0.03^{\mathrm{a}, 1}$ & $0.565 \pm 0.02^{\mathrm{a}, 1}$ \\
Springiness (mm) & $18.2 \pm 0.21^{\mathrm{a}, 1}$ & $18.8 \pm 0.04^{\mathrm{b}, 1}$ & $17.9 \pm 0.81^{\mathrm{a}, 1}$ & $18.9 \pm 0.42^{\mathrm{b}, 1}$ \\
Gumminess (N) & $0.430 \pm 0.02^{\mathrm{a}, 1}$ & $0.555 \pm 0.03^{\mathrm{b}, 1}$ & $0.379 \pm 0.02^{\mathrm{a}, 2}$ & $0.569 \pm 0.07^{\mathrm{b}, 1}$ \\
Chewiness (J) & $0.0078 \pm 0.0003^{\mathrm{a}, 1}$ & $0.0105 \pm 0.0004^{\mathrm{b}, 1}$ & $0.0068 \pm 0.0004^{\mathrm{a}, 2}$ & $0.0108 \pm 0.0017^{\mathrm{b}, 1}$ \\
Adhesiveness (J) & $0.00144 \pm 0.0003^{\mathrm{a}, 1}$ & $0.00155 \pm 0.0003^{\mathrm{a}, 1}$ & $0.00165 \pm 0.0007^{\mathrm{a}, 2}$ & $0.00171 \pm 0.0003^{\mathrm{a}, 1}$ \\
Spreadability (N mm) & $0.0462 \pm 0.004^{\mathrm{a}, 1}$ & $0.0603 \pm 0.006^{\mathrm{b}, 1}$ & $0.0440 \pm 0.001^{\mathrm{a}, 1}$ & $0.0573 \pm 0.009^{\mathrm{b}, 1}$ \\
\hline
\end{tabular}

$N S$ without salt, $S$ with salt

a, b Effect of salt: within the same liver/fat ratio, means with different letter indicate significant difference at $p<0.05$

${ }^{1,2}$ Effect of liver/fat ratio: within the same salt variant, means with different number indicate significance difference at $p<0.05$

Colmenero, Ayo and Carballo (2005) also found that the hardness, springiness, chewiness and gumminess of frankfurters increased with salt. Barbut et al. (2009) concluded that increasing the salt level from 10.0 to $30.0 \mathrm{~g} / \mathrm{kg}$ in chicken meat batters increased the springiness and chewiness. Hand et al. (1987) showed that low-fat frankfurters containing 2.0 or $2.5 \%$ salt had a harder texture than those containing $1.5 \%$ salt.

The increase in hardness and spreadability on the addition of salt can again be explained by the microstructural characteristics as discussed above. As seen from the micrographs (Fig. 2), addition of salt resulted in smaller fat globules (only for $35 / 35$ ) because of a more intensive solubilisation of the liver proteins. According to Cassens and Schmidt (1979), meat products with smaller lipid globules have greater resistance to penetration than meat products with larger lipid globules. This was attributed to a higher number of small globules present in a given volume with more protein membrane surrounding them, thereby offering more resistance. Steen et al. (2013) studied the effect of the same amounts of salt on the viscoelastic properties of liver paste and also observed an increase in the viscoelastic properties of liver paste (determined by $\mathrm{G}^{\prime}, \mathrm{G}^{\prime \prime}$ and LVR) with addition of salt.

A lower liver/fat ratio did not have an important impact on the texture and spreadability of liver paste, although the hardness, gumminess, chewiness and adhesiveness values of the liver pastes without salt were slightly decreased. The influence of fat and/or protein level on texture has been widely studied in all kinds of cold meat emulsions like liver paste (Estévez et al. 2005), frankfurters (Allais et al. 2004; Baker et al. 1969; Hughes et al. 1997; Simon et al. 1965; Sylvia et al. 1994,...), beef meat emulsions (Youssef and Barbut 2009, 2010), bologna sausages (Jiménez-Colmenero et al. 1995), and so on. The different composition and the conflicting results however make it difficult to evaluate and compare the effect of the lean/fat ratio with the results of the present study. Also for the effect of liver/fat ratio on texture, there is no literature available on liver paste. Only the effect of fat reduction on texture has been studied. Delgado-Pando et al. $(2011,2012) \&$ Hong et al. (2004) showed that reducing the fat content in spreadable liver paste resulted in a decrease of the textural parameters. This is in contrast to the results obtained in this work, probably because the fat reduction was achieved by increasing the moisture level instead of the protein level as in this study. After all, it is known that (meat) proteins, which are more prominently present in the $35 / 35$ liver pastes, form a gel matrix and thus contribute to the texture (hardness) in processed meat products (with low moisture contents) (JiménezColmenero et al. 1995). Furthermore, the literature indicates that fat also contributes to the texture of emulsified meat products. It is assumed that the hardness of a lipid system is inter alia function of its solid fat content and the microstructural factors associated with it (Braipson-Danthine and Deroanne 2004).

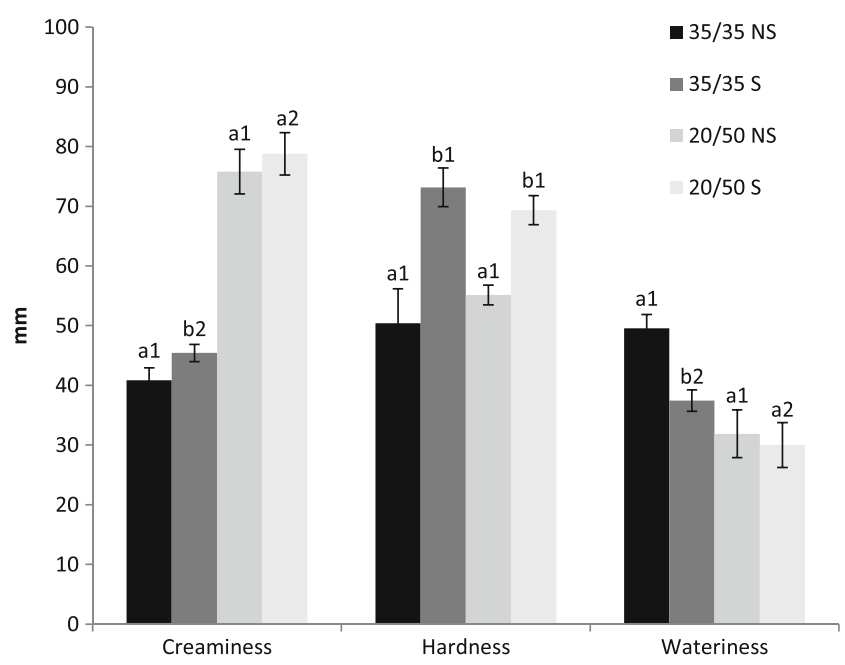

Fig. 4 Sensory mouth feel attributes from liver paste emulsions prepared with liver/fat ratio $35 / 35$ or $20 / 50$, with (S) our without salt (NS). Means and standard deviation are presented $\left(C_{n}=27\right) .{ }^{a, b}$ Effect of salt: within the same liver/fat ratio, means with different letter indicate significant difference at $p<0.05 .{ }^{1,}{ }^{2}$ Effect of liver/fat ratio: within the same salt variant, means with different number indicate significant difference at $p<0.05$ 
Both raw materials (protein and fat) are thus important for the texture of liver paste and influence its texture. This might be the reason why the effect of a different liver/fat ratio was not noticeable in the liver pastes containing salt. Steen et al. (2013) studied the effect of the same liver/fat ratios on the viscoelastic properties of liver paste and concluded that the effect of a higher liver/fat ratio was also not noticeable in the structure of liver paste, determined by $\mathrm{G}^{\prime}$ and $\mathrm{G}^{\prime \prime}$. However, the structural impact of the proteins was more stress-resistant than the structural contribution of fat crystallization, determined by a longer LVR for liver pastes $35 / 35$.

\section{Descriptive Sensory Analysis}

The sensory properties of the four liver paste variants were analysed by a sensory panel. The focus of this analysis was on studying the effect of salt and liver/fat ratio on the mouth feel and texture attributes. The results are shown in Fig. 4. Creaminess is a dominant attribute in the overall liking of spreadable liver paste. According to de Wijk et al. (2003), creaminess can be defined as 'a range of sensations typically associated with fat content, such as full and sweet taste, compact, smooth, not rough, not dry, with a velvet (not oily) coating. Food disintegrates at a moderate rate'. As seen from Fig. 4, the creaminess perception is highest for the liver pastes with a low liver/fat ratio and thus a higher proportion of fat, as expected. Salt only influenced the creaminess of the liver paste $35 / 35$, but to a much smaller extent than the liver/fat level.

Similar to the instrumental hardness, addition of salt significantly increased the sensory hardness. The effect of salt was more pronounced for liver paste 35/35. Matulis et al. (1995) also showed that salt increased the sensory hardness of cold meat emulsion sausages. As for the effect of liver/fat ratio, no difference in sensory hardness between the liver pastes $35 / 35$ and 20/50 was found, regardless of the salt content. This is in agreement with the findings observed for the instrumental hardness where the liver/fat ratio also did not affect the instrumental hardness of the liver paste containing salt. However, although significant, a small decrease in instrumental hardness of the liver paste without salt was obtained with a lower liver/fat ratio. This decrease is probably too small to be observable by a sensory panel. In conclusion, the results of the sensory hardness correspond to those of the instrumental hardness.

According to Tournier et al. (2007), wateriness is defined as the perception of water content in the product. Addition of salt decreased the wateriness of the liver paste $35 / 35$, while liver paste 20/50 was not affected. A decrease in the liver/fat ratio resulted in a noticeable significant decrease in wateriness intensity. The effect was more pronounced for the liver paste without salt. This was due to the substitution of fat by liver which has a higher moisture content.
The effect of liver/fat ratio and salt on the sensory attribute graininess is not shown because no significant differences were observed between the four treatments.

\section{Conclusion}

Liver paste is a hot emulsion which consists of emulsified zones of fat globules surrounded by a protein layer and dissolved proteins in a continuous phase forming a gel matrix. As seen from the micrographs, addition of salt led to smaller fat globules which was also reflected in the higher emulsion stability and especially in the increased fat binding properties of liver paste resulting in a harder, less spreadable product. It is assumed that with salt, more proteins are available to act as an emulsifier and for gel formation. As for the effect of liver/fat ratio, a decrease resulted in the formation of a more heterogeneous emulsion with bigger fat globules because less proteins were dissolved in the continuous phase and available for adsorption at the oil/water interface. This caused fat and liquid migration out of these products. Although less stable emulsions were formed with a lower liver/fat ratio, no differences in hardness could be obtained between the liver pastes $35 / 35$ and 20/50. Apparently, both liver protein gelation and fat crystallization contribute to the hardness of liver paste. In order to gain further insight into the contribution of liver proteins and fat crystals to the structure of liver paste, it would be interesting to study the intrinsic structure forming ability of these constituents. More specifically, insight is needed into the emulsifying and gelling capacity of liver proteins, and the crystallization behaviour of fat.

Acknowledgments The authors acknowledge the financial support from the Research Council of the Katholieke Universiteit Leuven, in particular the Industrial Research Fund and the Fund for Stimulation of Scientific Research for associated technical universities.

\section{References}

AFNOR (1999) Viandes et produits à base de viande - Préparation d'une coupe histologique - Technique en paraffine. NF V04-417, Cedex, France.

Allais, I. (2010). Emulsification. In Toldrá (Ed.), Handbook of meat processing (pp. 143-168). Iowa, USA: Blackwell Publishing.

Allais, I., Christophe, V., Pierre, A., \& Dufour, E. (2004). A rapid method based on front-face fluorescence spectroscopy for the monitoring of the texture of meat emulsions and frankfurters. Meat Science, 67, 219-229.

Baker, R. C., Darfler, J., \& Vadehra, D. V. (1969). Type and level of fat and amount of protein and their effect on the quality of chicken frankfurters. Food Technology, 23(1), 808-811.

Barbut, S., Somboonpanyakul, P., Quinton, M., \& Smith, A. (2009). Effect of malva nut gum (purified and crude), sodium chloride and phosphate on cooking, texture, colour, rheology and microstructure of different chicken meat batters. Britsh Poultry Science, 50(1), 83-94. 
Bourne, M. C. (1978). Texture profile analysis. Food Technology, 32(7), $62-66$.

Braipson-Danthine, S., \& Deroanne, C. (2004). Influence of SFC, microstructure and polymorphism on texture (hardness) of binary blends of fats involved in the preparation of industrial shortenings. Food Research International, 37, 941-948.

Carballo, J., Mota, N., Barreto, G., \& Colmenero, F. J. (1995). Binding properties and colour of bologna sausage made with varying fat levels, protein levels and cooking temperature. Meat Science, 41(3), 301-313.

Cassens, R. G., \& Schmidt, R. (1979). Texture and lipid phase morphology of some processed meats. Journal of Food Science, 44(4), 1256-1257.

Cheong, S. H., \& Fischer, A. (1991). Feinzerkleinerte leberwurst: wirkungsweise und optimierung von emulgatoren, teil 1. (Finely comminuted liver sausage: mode of action and optimization of emulsifiers, part 1.). Fleischwirtschaft, 71, 1148-1158.

Cheong, S. H., \& Fischer, A. (1992). Feinzerkleinerte leberwurst: wirkungsweise und optimierung von emulgatoren, teil 2. (Finely comminuted liver sausage: mode of action and optimization of emulsifiers, part 2.). Fleischwirtschaft, 72, 142-149.

Cheong, S. H., \& Fischer, A. (1993). Rasterelektronenmikroscopische deutung der wirkungsweise von emulgatoren auf die fettstabilisierung bei feinzerkleinerter leberwurst. (Interpretation of the action of emulsifiers on fat stabilization in finely comminuted liver sausage as seen under the scanning electron microscope.). Fleischwirtschaft, 73, 677-683.

de Wijk, R. A., van Gemert, L. J., Terpstra, M. E. J., \& Wilkinson, C. L. (2003). Texture of semi-solids; sensory and instrumental measurements on vanilla custard desserts. Food Quality and Preference, 14(4), 305-317.

Delgado-Pando, G., Cofrades, S., Rodríguez-Salas, L., \& JiménezColmenero, F. (2011). A healthier oil combination and konjac gel as functional ingredients in low-fat pork liver pâté. Meat Science, 88 , 241-284.

Delgado-Pando, G., Cofrades, S., Ruiz-Capillas, C., Triki, M., \& Jiménez-Colmenero, F. (2012). Low-fat pork liver pâtés enriched with n-3 PUFA/konjac gel: dynamic rheological properties and technological behavior during chill storage. Meat Science, 92, $44-52$.

Estévez, M., Ventanas, S., \& Cava, R. (2005). Physicochemical properties and oxidative stability of liver pâté as affected by fat content. Food Chemistry, 92, 449-457.

Fischer, A., Cheong, S. H., \& Jaud, D. (1991). Finely comminuted liver sausage. How the normal commercial emulsifiers work. Fleischwirtschaft, 71, 780-783.

Hammer, G. F. (1981). Zur verbesserung der leberwurstherstellung. (Improving liver sausage manufacture.). Fleischwirtschaft, 61, 524-531.

Hammer, G. F. (1988a). Technologische wirkung von veresterten monoglyceriden und Ei bei feinzerkleinerten leberwurst. (The technological effect of esterified monoglycerides and egg in finely comminuted liver sausage.). Fleischwirtschaft, 68, 12241231.

Hammer, G. F. (1988b). Technologische wirkung von caseinat und fremdwasser bei Fein zerkleinerten leberwurst. (The technological effects of caseinate and extraneous water in finely comminuted liver sausage.). Fleischwirtschaft, 68, 1336-1347.

Hammersley AP (1998) FIT2D V9.129 Reference Manual V3.1. ESRF Internal Report, ESRF98HA01T, Grenoble, France.

Hand, L. W., Hollingsworth, C. A., Calkins, C. R., \& Mandigo, R. W. (1987). Effects of preblending, reduced fat and salt levels on frankfurter characteristics. Journal of Food Science, 52(5), 1149-1151.

Hilmes C, Cheong SH \& Fischer A (1993) Microstructure and stability of liver sausage as influenced by liver content. Die Fleischerei, 44, III-V.
Hong, G. P., Lee, S., \& Min, S. G. (2004). Effects of substituted levels of added water for fat on the quality characteristics of spreadable liver sausage. Food Science and Biotechnology, 13(4), 397-402.

Hughes, E., Cofrades, S., \& Tory, D. J. (1997). Effects of fat level, oat fibre and carragenan on frankfurters formulated with 5, 12 and $30 \%$ fat. Meat Science, 45, 373-281.

Jaud, D., Schneider, K., Hilmes, C., Cheong, S. H., \& Fisher, A. (1998). Feinzerkleinerte leberwurst: einfluss verschiedener fette auf die stabilität. Teil 3: fettseparation der endprodukte unter berücksichtiging der standzeit. (Finely comminuted liver sausage: effect of different fats on stability. Part 3: Fat separation of final products with regard to the proof time. Fleischwirstschaft, 78, 664-670.

Jiménez-Colmenero, F., Barreto, G., Mota, N., \& Carballo, J. (1995). Influence of protein and fat content and cooking temperature on texture and sensory evaluation of bologna sausage. LebensmittelWissenschaft und Technologie, 28, 481-487.

Jiménez-Colmenero, F., Ayo, M. J., \& Carballo, J. (2005). Physicochemical properties of low sodium frankfurter with added walnut: effect of transglutaminase combined with caseinate, $\mathrm{KCl}$ and dietary fibre as salt replacers. Meat Science, 69, 781-788.

Katsaras, K., Linke, H., \& Hammer, G. (1987). Morphology of spreadable sausages of liver sausage type. Fleischwirtschaft, 67, 949-951.

Lurueña-Martinez, M. A., Vivar-Quintana, A. M., \& Revilla, I. (2004). Effect of locust bean/xanthan gum addition and replacement of pork fat with olive oil on the quality characteristics of low-fat frankfurters. Meat Science, 68, 383-389.

Martoja, R., \& Martoja, M. (1967). Initiation aux techniques de l'histologie animale. Paris, France: Paris Masson.

Matulis, R. J., McKeith, J. W., Sutherland, J. W., \& Brewer, M. S. (1995). Sensory characteristics of frankfurters as affected by fat, salt, and pH. Journal of Food Science, 60, 42-47.

McClements, D. J. (2005). Food emulsions: principles, practice, and techniques. Florida, USA: CRC Press.

Miklos, R., Xu, X., \& Lametsch, R. (2011). Application of pork fat diacylglycerols in meat emulsions. Meat Science, 87, 202-205.

Nuckles, R. O., Smith, D. M., \& Merkel, R. A. (1990). Meat by-product protein composition and functional properties in model systems. Journal of Food Science, 55, 640-643.

Perlo, F., Gago-Gago, A., Rosmini, M., Cervera-Perez, R., PerezAlvarez, J., Pagan-Moreno, M., et al. (1994). Modification of physico-chemical and colour parameters during the marketing of 'paté'. Meat Science, 41(3), 325-333.

Pyrcz, J., Pietronczyck, K., Kowalski, R., \& Danyluk, B. (2005). Functions of emulsifiers in developing quality homogenized liver sausage type of products. Medycyna Weterynaryjna, 61(10), 11691174.

Pyrcz, J., Pietronczyck, K., Kowalski, R., \& Danyluk, B. (2006). The effect of species origin of liver on quality of liver pate type sausage. Electronic Journal of Polish Agricultural Universities, 9(2).

Russell, E. A., Lynch, A., Lynch, P. B., \& Kerry, J. P. (2003). Quality and shelf life of duck liver pâté as influenced by dietary supplementation with $\alpha$-tocopheryl acetate and various fat sources. Journal of Food Science, 68, 799-802.

Schneider, K., Jaud, D., Hilmes, C., Cheong, S. H., \& Fischer, A. (1998). Feinzerkleinerte leberwurst: einfluss verschiedener fette auf die stabilität teil 2: destabilisierung der rohmassen unter berücksichtiging der standzeit. (Finely comminuted liver sausage: effect of different fats on stability. Part 2: destabilization of raw batter with regard to thermal retardation.). Fleischwirtschaft, 78, 464-470.

Simon, S., Field, J. C., Kramlich, W. E., \& Tauber, F. W. (1965). Factors affecting frankfurter texture and a method of measurement. Food Technology, 19(3), 410-416.

Steen, L., Fraeye, I., De Mey, E., Goemaere, O., Paelinck, H., \& Foubert, I. (2013). Effect of salt and liver/fat ratio on viscoelastic properties of 
liver paste and its intermediates. Food and Bioprocess Technology. doi:10.1007/s11947-012-1038-8.

Sylvia, S. F., Claus, J. R., Marrito, N. G., \& Rigel, W. N. (1994). Low-fat, high moisture frankfurters: effects of temperature and water during extended mixing. Journal of Food Science, 59, 937-940.

Tournier, C., Martin, C., Guichard, E., Issanchou, S., \& Sulmont-Rossé, C. (2007). Contribution to the understanding of consumers' creaminess concept: a sensory and a verbal approach. International Dairy Journal, 17(5), 555-564.

Youssef, M. K., \& Barbut, S. (2009). Effects of protein level and fat/oil on emulsion stability, texture, microstructure and color of meat batters. Meat Science, 82, 228-233.

Youssef, M. K., \& Barbut, S. (2010). Physicochemical effects of the lipid phase and protein level on meat emulsion stability, texture, and microstructure. Journal of Food Science, 75(2), 108-114. 